\title{
Garino, Gossmann, Klein, and Polman to Chair 2003 MRS Spring Meeting
}

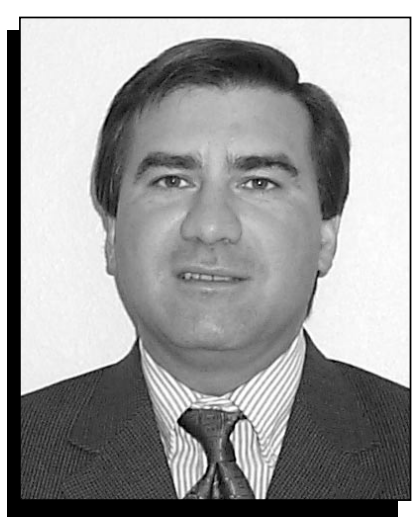

Terry Garino

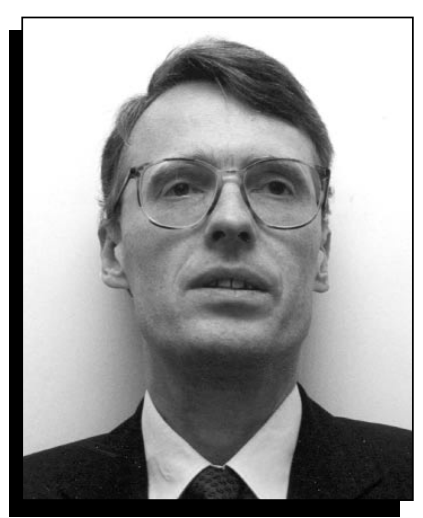

Hans-Joachim L. Gossmann

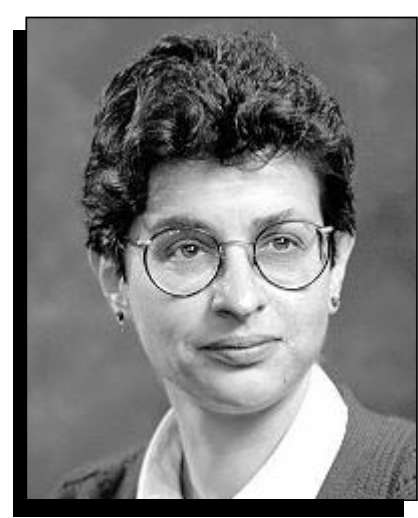

Lisa C. Klein

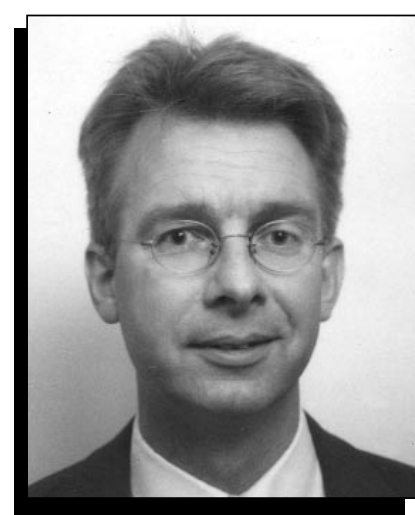

Albert Polman
The 2003 Materials Research Society Spring Meeting in San Francisco, April 21-25, will be chaired by Terry Garino of Sandia National Laboratories, HansJoachim L. Gossmann of Agere Systems, Lisa C. Klein of Rutgers University, and Albert Polman of FOM-Institute AMOLF. The program is currently set at 26 symposia gathered into four clusters: Electronic and Optoelectronic Materials, Molecular Materials and Biomaterials, Nanostructured Materials, and General.

Terry Garino is a principal member of the technical staff at Sandia National Laboratories in Albuquerque. He received a BS degree in ceramic engineering (1982) from the University of Illinois at UrbanaChampaign and a PhD degree in ceramic science (1987) from the Massachusetts Institute of Technology. His current research interests include processing and characterization of solid-oxide fuel-cell materials; sintering behavior of multimaterial systems; high-voltage electrical breakdown of compacted, oxidized metal powders; fabrication and sintering of sintered ceramic and metal microparts; characterization of density gradients in pressed ceramic compacts; and the behavior of silver/palladium materials during heating.

Hans-Joachim L. Gossmann is a distinguished member of the technical staff at Agere Systems. He received the MS and Diplom degrees in physics from the State University of New York (SUNY) at Albany and the University of Würzburg, Germany in 1979 and 1981, respectively.
In 1984, Gossmann earned his PhD degree in physics from SUNY-Albany, then joined AT\&T Bell Laboratories (now Bell Laboratories/Lucent Technologies). He recently moved with the semiconductor manufacturing part of Lucent Technologies to Agere Systems. Gossmann's research interests include Si molecularbeam epitaxy and in situ doping; ion-solid interactions; the study of native point defects and their interactions with dopants in Si and III-V materials; predictive, physics-based, process simulation; design and manufacturing of sub-100-nm Si devices, in particular, formation of contacts and junctions; and III-V-based rfdevices. Gossmann is the author or coauthor of over 150 technical papers and has more than 10 awarded or pending patents. He served as subject editor for the Encyclopedia of Materials: Science and Technology and was an MRS symposium co-organizer in 2000.

Lisa C. Klein is a professor of ceramic and materials engineering at Rutgers, the State University of New Jersey. She received a BS degree in metallurgy in 1973 and a PhD degree in ceramics in 1977 from the Materials Science and Engineering Department at the Massachusetts Institute of Technology. With Rutgers since 1977, Klein became a full professor in 1987. She has been a visiting scientist at Sandia National Laboratories in Albuquerque, New Mexico; the University of Grenoble in Grenoble, France; and Hebrew University in Jerusalem, Israel. Her current research interest is finding sol-gel applications in electrolytes, electrochromics, batteries, and fuel cells. Klein serves as principal editor for the Journal of Materials Research and has been a member of the National Materials Advisory Board of the National Research Council. She is the author of over 150 technical publications, and was a symposium co-organizer for MRS in 1999.

Albert Polman is a scientific group leader and head of the optoelectronic materials program at the FOM-Institute AMOLF in Amsterdam, The Netherlands. He received his master's degree in physics (1985) and his PhD degree in materials science and engineering (1989) from the University of Utrecht. From 1989 to 1991, he was a postdoctoral researcher at AT\&T Bell Laboratories. In 1991, he returned to AMOLF to start a new optoelectronic materials program. In 1996, he was appointed adjunct professor of materials science at Utrecht University. Polman's research interests include photonicbandgap materials, rare-earth-doped photonic materials, colloidal photonic materials, semiconductor nanocrystals, rareearth-doped semiconductors, as well as the fundamentals of ion-solid interactions. He has co-authored over 160 papers on optoelectronic materials, four conference proceedings, and is co-inventor on five patents. He has served MRS three times as a symposium organizer (1994, 1996, and 1997), and was a Volume Organizer for MRS Bulletin in 2000.

MIRTS

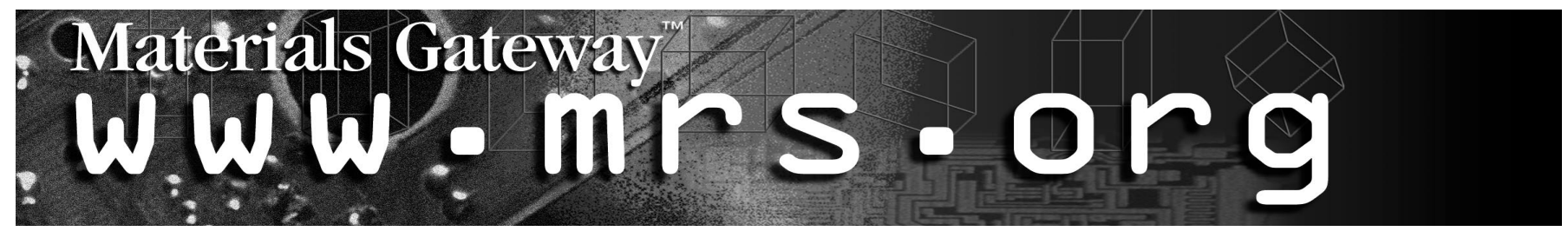

